called "indirect paraspinal collateral network monitoring." ${ }^{10}$ Regardless of the positioning of the optodes, available animal studies ${ }^{11,12}$ have shown promising correlations between NIRS data on regional oxygenation and spinal cord perfusion. Further clinical trials are deemed necessary to investigate if NIRS detected spinal oxygen saturation is an accurate modality for spinal cord blood flow.

In most studies, including the current one, the perfusion pressure with ACP is maintained at (or below) $50 \mathrm{~mm} \mathrm{Hg}$ to prevent any cerebral edema. However, one wonders whether a slightly higher ACP perfusion pressure and flow (closer to $60 \mathrm{~mm} \mathrm{Hg}$ ) or a lower degree of hypothermia $\left(<22^{\circ} \mathrm{C}\right)$ would have any impact on the NIRS-detected oxygen saturation of the spinal cord. Until we obtain an accurate modality to monitor spinal cord perfusion in real time (both intraoperatively and postoperatively), extra caution should be taken in total transverse aortic arch replacement when warmer temperatures during hypothermic circulatory arrest are used for long intervals.

\section{References}

1. Coselli JS, Green SY. Aortic arch repair today: open repair is best for most arch lesions. J Cardiovasc Surg (Torino). 2015;56:531-46.

2. Hanif H, Dubois L, Ouzounian M, Peterson MD, El-Hamamsy I, Dagenais F, et al. Aortic arch reconstructive surgery with conventional techniques vs frozen elephant trunk: a systematic review and meta-analysis. Can J Cardiol. 2018;34:262-73.
3. Settepani F, Cappai A, Basciu A, Barbone A, Tarelli G. Outcome of open total arch replacement in the modern era. J Vasc Surg. 2016;63:537-45.

4. Svensson LG. Protecting the brain and spinal cord in aortic arch surgery. Ann Cardiothorac Surg. 2018;7:345-50.

5. Kondoh H, Taniguchi K, Funatsu T, Toda K, Masai T, Takahashi T, et al. Total arch replacement with long elephant trunk anastomosed at the base of the innominate artery: a single-centre longitudinal experience. Eur J Cardiothorac Surg. 2012;42:840-8.

6. Shrestha M, Bachet J, Bavaria J, Carrel TP, De Paulis R, Di Bartolomeo R, et al. Current status and recommendations for use of the frozen elephant trunk technique: a position paper by the Vascular Domain of EACTS. Eur $J$ Cardiothorac Surg. 2015;47:759-69.

7. Kinoshita T, Yoshida H, Hachiro K, Suzuki T, Asai T. Spinal cord collateral flow during antegrade cerebral perfusion for aortic arch surgery. J Thorac Cardiovasc Surg. 2020;160:37-43.

8. Coselli JS, LeMaire SA, Preventza O, de la Cruz KI, Cooley DA, Price MD, et al. Outcomes of 3309 thoracoabdominal aortic aneurysm repairs. J Thorac Cardiovasc Surg. 2016;151:1323-37.

9. Boezeman RP, van Dongen EP, Morshuis WJ, Sonker U, Boezeman EH, Waanders FG, et al. Spinal near-infrared spectroscopy measurements during and after thoracoabdominal aortic aneurysm repair: a pilot study. Ann Thorac Surg. 2015;99:1267-74.

10. Etz CD, von Aspern K, Gudehus S, Luehr M, Girrbach FF, Ender J, et al. Nearinfrared spectroscopy monitoring of the collateral network prior to, during, and after thoracoabdominal aortic repair: a pilot study. Eur J Vasc Endovasc Surg. 2013;46:651-6.

11. LeMaire SA, Ochoa LN, Conklin LD, Widman RA, Clubb FJ Jr, Undar A, et al Transcutaneous near-infrared spectroscopy for detection of regional spinal ischemia during intercostal artery ligation: preliminary experimental results. $J$ Thorac Cardiovasc Surg. 2006;132:1150-5.

12. von Aspern K, Haunschild J, Ziemann M, Misfeld M, Mohr FW, Borger MA et al. Evaluation of collateral network near-infrared spectroscopy during and after segmental artery occlusion in a chronic large animal model. J Thorac Cardiovasc Surg. 2019;158:155-64.e5.

\title{
Commentary: No cord left behind
}

John Bozinovski, MD, MSc, and

Asvin M. Ganapathi, MD

Until recently, protection from end-organ injury during aortic arch surgery has focused on the brain. The primary means for organ protection was hypothermia, and because the organ most susceptible to ischemia is the brain, there

\footnotetext{
From the Division of Cardiac Surgery, The Ohio State University Wexner Medical Center, Columbus, Ohio.

Disclosures: Authors have nothing to disclose with regard to commercial support.

Received for publication July 26, 2019; accepted for publication July 29, 2019; available ahead of print Sept 5, 2019.

Address for reprints: John Bozinovski, MD, MSc, N816A Doan Hall, 410 W 10th

Ave, Columbus, OH 43210 (E-mail: jovan.bozinovski@osumc.edu).

J Thorac Cardiovasc Surg 2020;160:45-6

$0022-5223 / \$ 36.00$

Copyright (c) 2019 by The American Association for Thoracic Surgery

https://doi.org/10.1016/j.jtcvs.2019.07.119
}

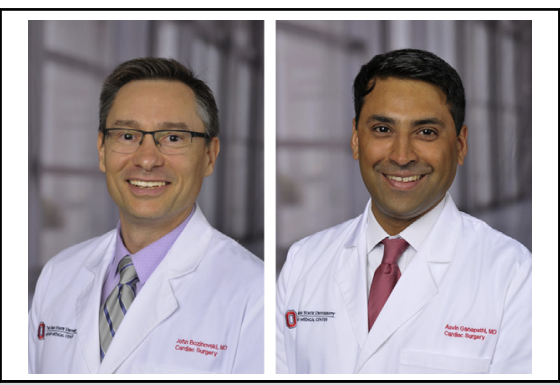

John Bozinovski, MD, MSc (left), and Asvin M Ganapathi, MD (right)

CENTRAL MESSAGE

The move to warmer tempera-

tures during aortic arch surgery

should not abandon consider-

ation of the risk to the spinal

cord. 
was less impetus to look at other organs. With the advent of selective antegrade cerebral perfusion during hypothermic circulatory arrest, arch procedures are being performed at warmer temperatures. The effect of this change on cerebral protection ${ }^{1}$ has been examined more frequently than its effects on other organs, such as the spinal cord. The study in this issue of the Journal of Kinoshita and colleagues ${ }^{2}$ does not specifically assess the effect of temperature; however, in light of the move toward warmer circulatory arrest, it provides valuable information. The study presumably examines blood flow to the spinal cord at different levels, from which inferences can be made about the importance of technique when performing arch procedures.

By using oximetry probes at the forehead and at the paravertebral T3 and T10 levels, Kinoshita and colleagues ${ }^{2}$ made an extrapolation about blood flow in the course of 18 circulatory arrest procedures. Although the findings were intuitive, the study provides evidence that the further anatomically from the source, the poorer is the flow. Further, during lower body circulatory arrest, Kinoshita and colleagues ${ }^{2}$ demonstrated that oximetry at $\mathrm{T} 3$ was not different from baseline and was stable, whereas at T10, oximetry fell precipitously and plateaued near its nadir after about 20 minutes. The assumption that we can make is that somewhere between the 2 levels, flow is sufficiently affected to become a concern.

Spinal cord injury (SCI) during aortic arch surgery is known to occur, but not with significant frequency. Frozen elephant trunk extension of arch intervention has been identified as a risk for SCI, ${ }^{4}$ but only some arch interventions require frozen elephant trunk extension. That lower body ischemic times are usually less than $90 \mathrm{mi}-$ nutes, and that "sufficient" hypothermia is being used likely has much to do with infrequency of SCI. As we get warmer with arch procedures, either we will find that SCI occurs more frequently, or we will more regularly incorporate distal perfusion techniques. A straightforward technique for distal aortic perfusion during arch surgery is described in a study by Tarola and associates, ${ }^{5}$ in which 62 patients were compared with 44 patients undergoing arch procedures without distal aortic perfusion. Surgery was performed at mean nadir temperatures of $26^{\circ} \mathrm{C}$ and $25^{\circ} \mathrm{C}$, and circulatory arrest times were 41 and 31 minutes, respectively. One patient in each group had SCI develop; both had an acute type A aortic dissection as the indication for the surgery. No patients undergoing arch surgery for isolated aneurysmal disease had SCI occur.

A weakness of the study of Kinoshita and colleagues ${ }^{2}$ is that direct measurement of blood flow to the regions of interest is not possible, but this is a fundamental problem with current technology. Near-infrared spectroscopy can only be assumed to reflect regional blood flow and organ perfusion. Assuming that to be true, the direction to rely more heavily on cooling, or to incorporate distal aortic perfusion, in procedures with potentially prolonged distal ischemia should be heeded.

\section{References}

1. Englum BR, He X, Gulack BC, Ganapathi AM, Mathew JP, Brennan JM, et al. Hypothermia and cerebral protection strategies in aortic arch surgery: a comparative effectiveness analysis from the STS Adult Cardiac Surgery Database. Euro J Cardiothorac Surg. 2017;52:492-8.

2. Kinoshita T, Yoshida H, Hachiro K, Suzuki T, Asai T. Spinal cord collateral flow during antegrade cerebral perfusion for aortic arch surgery. J Thorac Cardiovasc Surg. 2020;160:37-43.

3. Tokuda Y, Fujimoto K, Narita Y, Mutsuga M, Terazawa S, Ito H, et al. Spinal cord injury following aortic arch replacement. Surg Today. July 22, 2019 [Epub ahead of print].

4. Hanif H, Dubois L, Ouzounian M, Peterson MD, El-Hamamsy I, Dagenais F, et al; Canadian Thoracic Aortic Collaborative (CTAC) Investigators. Aortic arch reconstructive surgery with conventional techniques vs frozen elephant trunk: a systematic review and meta-analysis. Can J Cardiol. 2018; 34:262-73.

5. Tarola CL, Lesenno KL, Gelinas JJ, Jones PM, Fernandes P, Fox SA, et al. Whole body perfusion strategy for aortic arch repair under moderate hypothermia. Perfusion. 2018:33:254-63. 